\title{
DEFINIENDO LAS REGLAS DEL JUEGO: CALDERÓN Y EL ESPACIO VIRTUAL
}

Francisco Javier López Martín

Department of Modern Languages

Fellows Hall

Denison University

43023. Granville. Ohio. USA

lopezf@denison.edu

[Anuario calderoniano (ISSN: 1888-8046), 5, 2012, pp. 71-83]

\begin{abstract}
¿Qué es la vida? Una ilusión, una sombra, una ficción, y el mayor bien es pequeño: que toda la vida es sueño, y los sueños, sueños son.
\end{abstract}

Así termina lamentándose Segismundo en la jornada segunda de La vida es sueño. Por otra parte, reconocemos que lo que experimentamos es lo real y desarrollamos nuestra existencia configurando esa realidad con nuestros actos. En consecuencia la realidad tiene una connotación individual que trasciende cualquier estudio o descripción generalista. La realidad es siempre subjetiva, depende de la experiencia 
histórica del sujeto que la concibe y de las circunstancias del momento en que es analizada.

Solo cuando la vivencia personal, convertida en imágenes, se integra mentalmente en el conjunto del entramado psíquico vital, se puede generar una nueva forma de realidad, la creada por la imaginación y los sueños. La realidad, a su vez, es copiada por el mundo literario, por el mundo del celuloide y finalmente por los ordenadores para desarrollar entornos virtuales. A continuación analizaré el espacio virtual que proponen, hoy en día, distintos juegos de ordenador y el espacio virtual que presenta Calderón en algunas de sus obras. Es decir, exploraré el espacio en que Calderón incorpora lo real y la imagen para conseguir que el espectador genere el espacio mental en el que se desarrolla la obra y estableceré relaciones con el modo en que, tres siglos después, los videojuegos producen la realidad virtual e involucran, también, al espectador en ella.

Por virtual se entiende algo que es simulado, a partir de elementos reales, con la finalidad de que se perciba como verosímil por los sentidos de aquel que se adentra en su estructura ${ }^{1}$. En 1965 Ivan Sutherland, reconocido como el padre de la realidad virtual, publicó The Ultimate Display en donde exponía que los ordenadores proporcionarían una ventana hacia los mundos virtuales ${ }^{2}$. Hoy en día los entornos de realidad virtual permiten que el individuo interactúe con los programas de ordenador creando realidades ficticias, sentidas como reales.

Las empresas de videojuegos siguen produciendo y vendiendo, cada vez más, los llamados mmorpgs (massively multiplayer online role-playing games), juegos que ofrecen un mundo virtual en el que los consumidores pueden llegar a ser héroes, ganar dinero y desarrollar una vida paralela, por un pago mensual o gratuitamente, pagando únicamente por objetos y servicios que mejoran la experiencia.

En esta paradójica realidad social virtual se manifiestan los sentimientos individuales multiplicados espectacularmente, debido a la

1 «Virtual Reality uses computers to create 3D environments in which one can navigate and interact. Navigation implies the ability to move around and explore the features of a 3D scene, such as walking through a forest. Interaction means the ability to select and manipulate objects in the scene, for instance, grabbing and examining a flower found in the forest». Gutiérrez, 2008, p. 1.

2 Gutiérrez, 2008, p. 5. 
desaparición de los controles morales que establece la sociedad de la realidad no virtual. De forma que, ante el auge fantástico de los programas de realidad virtual, se podría fácilmente deducir que, en el estado de crisis que vivimos, ante el hundimiento de la economía mundial, con la destrucción de las pequeñas empresas y un aumento abrumador del desempleo, la realidad virtual bien podría ser para muchos la pócima mágica que permite la evasión de aquellos problemas. Un verdadero catalizador de emociones.

Evidentemente han existido otras muchas épocas de crisis en la historia, sin embargo, teniendo en cuenta estas características, no resultaría aventurado, aunque no es el objetivo de este artículo, establecer los paralelismos que existen entre la crisis económica de principios de nuestro siglo y aquella otra crisis del conocimiento, que se inició en el siglo XVI a partir del encuentro con América. Comienza un proceso de crisis e inseguridad provocado porque Europa y, en concreto, España, se enfrentan ante una situación única: la reconfiguración del mundo conocido. El nuevo mapa del mundo le obliga a cambiar el sistema de mercado, se deshace el mito del Non-Plus Ultra y con ello su sensación de seguridad en torno al Mare Nostrum y se cartografian los límites del Atlántico. Estos y otros cambios provocan una crisis del conocimiento que se refleja en las manifestaciones sociales, artísticas y culturales de la época. Pensadores como Descartes, Bacon, Leibniz, Galileo o Newton ponen en duda el concepto de realidad con su método inductivo-observacional y buscan nuevos sistemas para acercarse a ella. El teocentrismo es sustituido por un antropocentrismo humanista y España se ve incapaz de mantener su imperio y se declara en bancarrota. Todo ello genera un paradigma epistémico específico que inicia la Modernidad. Durante el siglo XVII, en este ambiente de inseguridad económica y social, Calderón de la Barca ofrece al público español obras como La vida es sueño o Eco y Narciso, en las que juega con el concepto de realidad e imagen.

A lo largo del siglo xx distintos campos de conocimiento han seguido explorando la realidad como conjunto así como la interacción del ser humano con aquello que le rodea. La fenomenología de Husserl desarrolla un estudio sobre los juicios, las percepciones y las emociones en un intento por comprender la estructura de la consciencia en el ser humano. Por su parte, la neurología investiga el entramado cerebral para descubrir la parte del cerebro que nos permite reconocer 
lo real, mientras la biología busca en el mapa genético humano las claves del comportamiento. La literatura, el cine y más recientemente Internet se han convertido en plataformas que permiten la presentación y desarrollo de otras realidades.

Desde los años 80, hipertexto e Internet han evolucionado, ganando terreno en nuestros hogares hasta convertirse en elementos imprescindibles en la vida cotidiana de millones de habitantes. La velocidad en la comunicación y el espacio abierto por Internet permiten el creciente flujo y acceso a la información, organizado mediante hipertextos. Su estructura copia o reproduce el modo en que la información fluye en la realidad, de manera que Internet se convierte, para muchos, en una alternativa a la realidad. Jacob Nielsen ${ }^{3}$ establece que las características del hipertexto son la no linealidad, la exploración, la prioridad del contenido sobre la forma, el uso del lenguaje, la integración de diversos elementos mediáticos y el uso de enlaces para desarrollar la información. Las tres primeras son características enfocadas a la experiencia del lector / espectador mientras que el resto pertenece a la estructura misma del hipertexto. Ambos elementos son fundamentales para crear el espacio virtual que proporciona Internet, ya que, a través de la experiencia del sujeto, la información se transforma en imagen y en vivencia. Por tanto, si la experiencia diaria es un conjunto de imágenes mentales construidas a partir de las informaciones recogidas por los sentidos, lo virtual sería una más de las imágenes vividas por el espectador. De este modo, se puede entender virtualidad y realidad en una relación simbiótica en donde la información cruza ambas esferas y llega al lector lista para ser asimilada.

Internet se compone de diversos nodos informativos o mónadas ${ }^{4}$, por su parecido con las de Leibniz, que desarrollan aspectos concretos de la realidad y que se conectan entre sí a través de enlaces. El espectador es quien decide las mónadas que visita y, en definitiva, la perspectiva que adopta. Pero además la propia creación establece contacto con el individuo en una relación simbiótica que impide la se-

3 Nielsen, 1990, p. 21.

${ }^{4}$ La mónada, según Leibniz, corresponde con la unidad y contiene representado el mundo. Charlie Dunbar comenta al respecto que según Leibniz, «at every moment each monad mirrors the whole universe from its own point of view». Dunbar, 1975, p. 96. 
paración entre lo real y lo virtual. De hecho, es la información recibida por el espectador la que potencia una acción o un posicionamiento fuera del marco de Internet. Esto es posible porque la pantalla del ordenador funciona como ventana que comunica la realidad con una infinitud de otras realidades virtuales. Entre la maraña de nodos que forman Internet, los videojuegos no son sino una mónada más en la que el jugador debe interactuar con el mundo que le propone un equipo de desarrolladores. El usuario, mediante su participación activa, crea un enlace, investiga el mundo propuesto y toma decisiones que afectarán su experiencia en el juego.

La industria del videojuego ofrece la oportunidad de vivir diversas experiencias aisladas del mundo real. La mayoría de juegos escogen convertir al consumidor en el héroe de una historia, con principio y fin. Sin embargo, una vez que el jugador haya explorado y agotado las posibilidades limitadas que se le presentan, es decir, cuando el usuario establece un mapa mental del mundo propuesto, el juego deja de tener interés. No es necesario revisitar ese mundo en cuestión porque carece de profundidad.

El videojuego Diablo ${ }^{5}$ pertenece, aparentemente, al conjunto de juegos que venden una experiencia lineal al espectador, sin embargo más allá de su apariencia nos encontramos ante un videojuego con un alto nivel de complejidad. A lo largo de dieciseis niveles, el personaje principal se adentra en el inframundo para eliminar a sus enemigos y abrirse paso hasta la morada de Diablo. Sin embargo, esta bajada a los infiernos requiere un esfuerzo activo por parte del jugador, quien se encuentra perdido en un laberinto de pasadizos plagados de trampas, salas secretas y tesoros. A medida que el personaje se mueve se descubren retazos de la realidad que debe explorar. Esta exploración constante atrapa al espectador en las garras del laberinto, del rompecabezas que debe resolver para enfrentarse a un nuevo reto.

La estructura del laberinto implica, por un lado, una creación laboriosa, concebida para esconder y defender un secreto y así evitar que los intrusos lo descubran; por otro, el laberinto constituye un reto, un obstáculo que debe ser vencido. La experiencia de quien se adentra en el laberinto es de desorientación, hasta que tras conseguir memorizar los distintos recovecos consigue familiarizarse con el laberin-

${ }^{5}$ Blizzard North, 1996. 
to y descubrir su secreto. Como expone Angela Ndalianis siguiendo a Calabrese, «[r]elying on a game based on a labyrinth, players discover the "pleasure of becoming lost" in an array of intertextual signs that are not merely alluded to, but are actually present» ${ }^{6}$. El jugador, por tanto, debe imponer orden en el aparente caos del laberinto.

Durante la primera mitad del siglo XviI, Calderón de la Barca desarrolla, asimismo, las posibilidades del laberinto y construye La vida es sueño como una maraña informativa que desafía el entendimiento del público. El espectador es transportado lejos de la realidad diaria y se ve inmerso en una trama de poder protagonizada por el rey de Polonia, Basilio, y su hijo Segismundo. Calderón organiza la información en forma de personajes que conforman nodos ${ }^{7}$ o mónadas que interactúan entre sí. Cada mónada contiene una parte de la realidad, de manera que si el espectador concentra su atención en un personaje concreto no puede dar sentido a la totalidad de la obra.

Calderón, además, cuestiona los referentes reales de los modos de comportamiento. Así se refleja cuando el autor define los papeles de cada personaje en relación, no con lo que el público espera ${ }^{8}$, sino con una realidad trastocada, haciendo que los acontecimientos sean impredecibles. El rey Basilio, por ejemplo, es un tirano que se basa en los astros para tomar sus decisiones ${ }^{9}$; el consejero y padre de Rosaura, Clotaldo, halaga a su rey en lugar de dar buenos consejos; Segismundo, el príncipe heredero, es encerrado en una torre como un animal y se convierte en un asesino; Rosaura debe disfrazarse y adoptar el papel

6 Ndalianis, 2004, p. 105.

7 «The text content was divided into information units that served as the hypertext nodes. Each unit had a title reflecting its content, and these titles were displayed on the overview providing access to the units». Rouet, 1996, p. 76.

${ }^{8}$ Lo que el público espera es la codificación de los valores propios que se tratan de rescatar durante el Barroco. Una sociedad regida por la honra, con un rey infalible. En La vida es sueño, Calderón representa estos conceptos distorsionados. Los agentes y los espectadores, entonces, deben aprender las reglas que le sirvan para decodificar la información, ya que la memoria funciona en la obra como obstáculo. El ejemplo claro de esta dinámica es el propio Segismundo, quien no posee memoria de la realidad puesto que ha pasado su vida encerrado en la torre. A medida que vive fuera de su mundo, aprende a relacionarse en el nuevo hábitat.

9 «Pues dando crédito yo / a los hados, que adivinos / me pronosticaban daños / en fatales vaticinios, / determiné de encerrar / la fiera que había nacido» (vv. 730735). 
de hombre para restaurar su honor. El cambio de papeles manifiesta la inutilidad de una realidad idealizada y, por lo tanto, el triunfo del mundo de las apariencias. Esta constante manipulación de la realidad es tan sutil que el tema de la obra queda oscurecido por las motivaciones de los distintos personajes, que confluirán en una guerra civil. Estas motivaciones funcionan como ruido informativo, como elementos que, al no poder ser explicados de manera satisfactoria, provocan confusión en el espectador. El público se enfrenta así a un espacio totalmente desconocido, en el que no puede extrapolar su experiencia. Las posiciones de los actores son impredecibles y cuando se desarrollan parecen desconcertar a unos espectadores que tratarán de ir uniendo piezas para poder encajar la trama en su mundo imaginario. Este ambiente confuso es palpable desde la primera escena: el público toma contacto con el espacio de la representación a través de Rosaura. Su entrada en la torre introduce al espectador en el laberinto y la figura de Segismundo no es sino la del hipogrifo violento que encierra los principios que rigen la realidad tejida por el dramaturgo.

Segismundo tiene los mismos problemas que el espectador para controlar la realidad que se le presenta. No puede hacer uso de su memoria para establecer relaciones con la información que le rodea porque ha estado excluido del mundo, encerrado en la torre. Una vez sale de ella, todo es nuevo para él y solo su experiencia diaria le permitirá confrontar los problemas que Calderón le plantea. De la misma manera que el espectador va descubriendo en el transcurso de la obra que las leyes del mundo real están controladas por las apariencias, Segismundo, a través de Clarín aprende de sus errores y se adapta a las circunstancias. De hecho Clarín, que representa la ocasión, es el ejemplo a seguir tanto por Segismundo como por el público a lo largo de la obra. Hasta prácticamente el final, el cómico sobrevive debido a su adaptación al medio. Únicamente cuando trata de evitar los acontecimientos e intenta adaptar el espacio a sus expectativas, durante la tercera jornada, fracasa (vv. 888-890).

En su segunda liberación de la torre, Segismundo se ve favorecido por la ocasión y la aprovecha, dando muestras de que puede moverse por los caminos del laberinto sin riesgo a perderse. La condena del soldado rebelde en la torre, donde antes se encontraba Segismundo, predice la perpetuación del laberinto, debido a que el soldado es cas- 
tigado injustamente ${ }^{10}$, al igual que él, con lo que se demuestra que el protagonista mimetiza el comportamiento de su padre. Segismundo, por tanto, consigue escapar de la torre para formar parte del complejo laberinto que lo rodea. Esta estructura circular muestra al espectador que no existe escapatoria del laberinto que recorre, sino distintos puntos de vista y, por lo tanto, distintos emplazamientos en el espacio que ha generado Calderón. El final circular de la obra invita a pensar en la repetición infinita de la estructura presentada, creando un espacio en el que el espectador se ve atrapado. Pero también suscita la idea de que cada entrada en el laberinto será vivida como una experiencia nueva, debido a la cantidad de información y caminos que contiene la obra.

El espacio imaginario de Calderón, para conseguir conectar con la realidad, se construye partiendo de sucesos verosímiles. No pretende exponer un mundo ajeno al espectador. El público necesita sentirse identificado, como sucede cuando Segismundo cree estar en un sueño. $Y$ es que el mundo virtual debe conservar referencias al mundo real para que el espectador sienta cierta familiaridad y pueda establecer puentes entre su realidad y el mundo que se le presenta. Esta estrategia es utilizada también en los videojuegos que venden la experiencia virtual al consumidor.

Second Life ${ }^{11}$ presenta un mundo similar al real, en el que el jugador toma el control de un personaje o residente que interactúa con otros jugadores y con el mundo virtual. Al contrario de lo que sucede en otros juegos y como expone acertadamente Alison McMahan, Second Life no plantea una historia al jugador sino que "was partly motivated by the "play-within-the-play" aspect, which they thought would be interesting to experiment with in a persistent world" (McMahan, p. 168). El jugador puede emprender negocios, conocer gente, divertirse en bares y, en general, prácticamente lo que se le ocurra. Todo le es familiar y puede experimentar con acciones o comportamientos que no desarrollaría en el mundo real ya que estos ac-

10 "The soldier is "the benefactor of the community", because he has benefited not only Segismundo (to whom he gives freedom and power, if not the throne), but also Rosaura, whose honour is restored, Basilio, who is chastened, and Poland, which gets Segismundo instead of Astolfo as the heir to the throne» (Hall, 1969, pp. 130131).

11 Linden Lab, 2003. 
tos no tienen consecuencias más allá del juego mismo. El usuario se desplaza con naturalidad entre su mundo y ese otro tan similar y a la vez tan diferente que le ofrece Second Life.

El juego de ordenador World of Warcraft ${ }^{12}$ reproduce, sin embargo, un mundo de fantasía ${ }^{13}$ que poco tiene que ver con la realidad. El jugador encarna la figura de un héroe que debe completar numerosas aventuras hasta alcanzar su destino. Todos los años, Blizzard introduce decoraciones apropiadas para la semana de Halloween y Navidad, celebrando las festividades con disfraces y fuegos artificiales. Además, el sistema económico de oferta y demanda de productos hace que el jugador tenga que hacer tareas repetitivas para conseguir materiales o dinero. Es decir, el jugador trabaja mientras juega. Estas irrupciones de lo real en el mundo virtual permiten una disolución de los planos de la realidad y la ficción generada por el juego.

Calderón, en la obra Eco y Narciso ${ }^{14}$, experimenta igualmente con la incorporación de elementos reales en el espacio imaginario para conseguir que los espectadores lo consideren como un mundo propio, realizando variaciones importantes a la historia clásica, entre las que destaca la inclusión de dos tiempos y dos realidades distintas: por un lado el mundo real, representado por la celebración del cumpleaños de Eco y por otro el mundo mítico en el que se enmarca. Esta convivencia, aunque resulta aporética, pasa desapercibida a los ojos del espectador, ya que ambos elementos están perfectamente entretejidos y convergen en el desarrollo del tema mítico.

Un primer análisis de la obra nos indica su carácter claramente mitológico. Calderón parece reescribir el famoso y conocido mito de Narciso con ciertos tintes didácticos. Sin embargo, al estudiarla como

12 Blizzard Entertainment, 2004.

13 "The attraction of fantasy is that it is precisely not real; its pleasures rest on fantasy as fantasy" (Krzywinska, 2007, p. 116).

14 Se acerca al mito contado por Ovidio en la Metamorfosis en el que la ninfa Eco, a la que Juno había castigado por encubrir los deslices de su marido, no podía hablar sino a través de la repetición de la última palabra que escuchara. Cuando Eco descubre la belleza de Narciso se enamora de este, pero es rechazada. Narciso, por su parte, tras contemplar su propio reflejo en un lago, se enamora de sí mismo y al intentar alcanzar la figura que ve en la orilla, cae en el agua y se ahoga. Entonces los dioses transforman a Narciso en una flor mientras Eco se consume y, finalmente, queda de ella solo su voz, en el interior de las montañas. 
espectáculo, es decir, teniendo en cuenta no solo el argumento y desarrollo de los personajes sino también los elementos que rodean la propia representación así como el papel de los espectadores en la obra, nos encontramos ante una exposición en torno al poder y al concepto de realidad (vv. 198-200). Calderón construye esta obra en dos planos o niveles que coexisten y que, a priori, resultarían irreconciliables. Por un lado, Eco y Narciso se desarrolla en el mundo mítico, que tiene como finalidad la explicación de los orígenes de la sociedad y actúa como modelo de ésta en el plano de la imaginación; y, por otro, en el mundo real, coincidiendo su representación, según los Anales de Madrid, con la celebración, en el Retiro, del cumpleaños de la princesa Margarita en el año 1661.

El mito, que durante el Renacimiento había servido como mediador entre el pasado desconocido de una sociedad y su identidad, pasa a ser, en esta obra, un mundo invadido por lo real, una imagen de la realidad o una interpretación de la misma. Para que sea posible esta interpretación el lector/espectador debe encontrar elementos comunes entre la ficción y la realidad que está viviendo e identificarse en la ficción. Es decir, la imagen debe incorporarse en el plano real. Sin embargo, Calderón lo plantea de forma contraria y consigue el mismo efecto. Mediante el uso de la alegoría, hace que la realidad invada y rodee al mito, transformándolo desde el interior por medio del cumpleaños de Eco y del transcurrir del tiempo en la obra, haciendo partícipes de la representación a la familia real, que estuvo presente fisicamente en la primera representación. El espectador, que ha sido llevado al plano de la imaginación, asimila la identidad de Eco como princesa, ya que ésta está presente en la representación.

Calderón, adelantándose en el tiempo, al igual que en los entornos virtuales, transforma una obra con motivo mitológico en un mundo invadido por la realidad del momento. Es entonces cuando la representación adquiere valor por sí misma, conteniendo la realidad y, a la vez, escapándose de ella. La invasión de lo real en el plano mitológico implica que lo concreto convive con valores absolutos.

Esta incorporación de la realidad en la imaginación nos muestra un mundo, el del Barroco, concebido como representación, como conjunto de imágenes superpuestas o, en palabras de Gilles Deleuze, como doblez:

[El Barroco] no remite a una esencia, sino más bien a una función operatoria, a un rasgo. No cesa de hacer pliegues. No inventa la cosa: ya 
había todos los pliegues procedentes de Oriente, los pliegues griegos, romanos, románicos, góticos, clásicos... Pero él curva y recurva los pliegues, los lleva hasta el infinito, pliegue sobre pliegue ${ }^{15}$.

Así, la representación funciona como ventana a través de la que se puede acceder a la realidad por medio de signos y referentes. Como expone Deleuze, durante el siglo XviI el arte explora los distintos niveles de la existencia y Calderón busca el espacio entre los distintos pliegues o, en relación a esta obra, las conexiones entre la realidad del mito y del mundo real para, siguiendo a Cascardi, «recognize illusion and then to find appropriate modes of action» ${ }^{16}$.

Tanto la metáfora del laberinto como la incorporación de elementos familiares en un espacio cuya pretensión debería ser separarse de la realidad, son estrategias que buscan la interacción entre el mundo creado y la figura del consumidor, ya sea en el teatro de Calderón o en la industria de los videojuegos. Igualmente, las diversas tramas que conforman La vida es sueño provocan desorientación en el espectador, creándole la necesidad de descubrir el mundo que Calderón plantea y lo consigue en la medida en que se posiciona como un elemento activo de ese mundo. El autor, en la misma línea de los juegos de ordenador actuales, permite al espectador una perspectiva parcial del argumento, proporcionándole cada vez una visión incompleta del mundo, lo que genera en el espectador una mayor avidez por continuar explorando y experimentando nuevamente la obra desde otras perspectivas. La realidad que propone Calderón, a imagen de la experiencia real, es inabarcable y el conocimiento que tiene el espectador de ella depende de las decisiones que toma y de su vivencia. El espacio que presenta contiene, a su vez, referencias y alusiones al mundo real, evitando trazar un límite que defina ese mundo, de manera que se pueda producir una rápida transición entre los contenidos experienciales del espectador y la realidad que vive en el mundo del teatro. En este sentido, Eco y Narciso es un ejemplo de esta traslación de lo real hasta formar parte del mundo imaginario y cómo el público se convierte, a su vez, en agente de la representación. Su paralelo en el entorno virtual actual sería el juego World of Warcraft,

15 Deleuze, 1989, p. 11.

${ }^{16}$ Cascardi, 1984, p. 133. 
donde el jugador, a pesar de encontrarse en un mundo fantástico, sigue celebrando festividades como la Navidad dentro del juego, permitiendo la inclusión de lo real en su espacio, admitiendo que la experiencia en el juego tiene el mismo valor que la experiencia de la realidad.

Tanto el espacio de la representación en las obras analizadas de Calderón como el virtual se pueden entender, por tanto, como mónadas que contienen el mundo y al ser exploradas pasan a formar parte de la experiencia del ser humano que, como espectador se encuentra al otro lado del escenario o de la pantalla. Ambos espacios nuevos cobran relevancia por aportar una solución a la necesidad que tienen los espectadores de evitar en lo posible la realidad que viven y de formar parte de una nueva experiencia. La ansiedad ante la inminencia de una batalla, la alegría por comprender finalmente las motivaciones de Segismundo, o por encontrar un tesoro, son reales, suceden en la mente del consumidor. El espectador y el jugador experimentan un mundo de imágenes y sensaciones que incorporan como parte de su experiencia vital, como otro aspecto más de una realidad que empieza y acaba en la imaginación.

En definitiva, Calderón consigue, al igual que los videojuegos actuales, implicar al espectador en la obra mediante los mecanismos cognitivos que incitan a la búsqueda de salidas y soluciones permanentemente. Y esto lo hace de una manera tan compleja y perfecta que, a pesar de escribir para el público del siglo XVII, el espectador de hoy en día puede verse también reflejado al contemplar sus obras. Para conseguirlo, Calderón utiliza estrategias de simulación de la realidad, con el fin de «enganchar» a partir de lo conocido o generar imágenes superpuestas que distorsionan la realidad para que el espectador encuentre sus propias respuestas. Al conseguirlo, se produce la catarsis, dando salida a la tensión conflictiva del mundo real en el que viven los espectadores. 


\section{BiBLIOGRAFÍA}

Calderón de la Barca, P., Eco y Narciso, ed. C. Aubrun, Paris, Centre de Recherches de l'Institut d'Études Hispaniques, 1963.

- La vida es sueño, ed. C. Morón Arroyo, Madrid, Cátedra, 1998.

Cascardi, A. J., The Limits of Illusion: A Critical Study of Calderón, Cambridge, Cambridge University Press, 1984.

Deleuze, G., El pliegue: Leibniz y el Barroco, trad. J.Vázquez y U. Larraceleta, Barcelona, Paidós, 1989.

Dunbar Broad, C., Leibniz: an Introduction, Cambridge, Cambridge University Press, 1975.

Gutiérrez Alonso, Vexo, M. A. F. y Thalmann, D., Stepping into Virtual Reality, London, Springer, 2008.

Hall, H. B., "Poetic Justice in La vida es sueño: a further comment», Bulletin of Hispanic Studies, 46, Liverpool, 1969, pp. 128-131.

Krzywinska, T., "Being a Determined Agent in (the) World of Warcraft: Text / Play / Identity", en Videogame, Player, Text, ed. B. Atkins y T. Krzywinska, Manchester, Manchester University Press, 2007.

McMahan, A., "Second Life: The game of Virtual Life», en Videogame, Player, Text, ed. B. Atkins y T. Krzywinska, Manchester, Manchester University Press, 2007.

Ndalianis, A., Neo-Baroque Aesthetics and Contemporary Entertainment, Media in Transition, Cambridge, MIT Press, 2004.

Nielsen, J., Hypertext and Hypermedia, Boston, Academic Press, 1990.

Ovidio Nasón, P., Metamorfosis, trad. C. Álvarez y R. M. Iglesias, Madrid, Cátedra, 2007.

Rouet, J. F., Hypertext and Cognition, Mahwah, Lawrence Erlbaum, 1996. 